depend on the physical qualities of the solvent, but on some chemical relationship between solvent and solute. It was suggested by the author that water, acting as an amphoteric electrolyte, could form a salt when mixed either with a strong acid or with a strong base, and that the high conductivity of mixtures of sulphuric acid and water, and the slight conductivity of mixtures of formic acid and water, were due neither to free acid nor to free water, but to the presence of an oxonium sulphate or formate in the liquid. The absence of conducting power in mixtures of water with hydrogen cyanide or formamide was attributed to the weakness of their acidic and basic qualities and the impossibility of combining them with water to form a salt-like electrolyte.

Prof. Guye, in a paper "On the nature of molecular associations in the special case of water," referred to a new formula by which the coefficient of association of a liquid might be deduced from its molecular surface energy, and showed that in the case of water at the boiling point it gave the factor $1 \cdot 96-$ a value considerably lower than that $(2.66)$ deduced by Ramsay and Shields, but agreeing closely with a value (I.98) deduced by Walden by another method. $\mathrm{He}$ also described the results of a calculation whereby the degree of association of liquid water could be calculated from the degree of association of steam on the assumption that the law of mass-action held good in both sases, and that the value of the constant remained the same throughout. Taking the figure $\mathrm{x} .089$ given by Bose for the association-factor of steam, the value $\mathbf{I} \cdot 99$ deduced for water was shown to agree satisfactorily with those derived by the other methods referred to above.

The values given by Prof. Guye for the coefficient of association of water at $100^{\circ}$ were, in the subsequent discussion, referred to by $\mathrm{Mr}$. Bousfield, who pointed out that (if correct) they would render untenable Sutherland's theory that liquid water is a binary mixture of trihydrol and dihydrol, since even at $100^{\circ}$ it would be necessary to assume the presence of considerable amounts of monohydrol in order to reduce the (average) association-factor below 2 .

The paper by Mr. W. R. Bousfield and Dr. T. M. Lowry, on "Liquid Water a Ternary Mixture. Solutionvolumes in Aqueous Solutions," was an extension to other solutes of some curious observations made five years previously in the case of aqueous solutions of caustic soda. The solution-volumes of the soda were found to vary largely with the concentration and with the temperature, the most remarkable feature of the variations being the occurrence of a maximum of solution-volume at about $60^{\circ} \mathrm{C}$. in liquids of all concentrations. The gradual conversion of the ordinary, slightly concave, expansion curve into a strongly convex curve had now been traced through a series of solutes-chloral hydrate, sugar, acetic acid, silver nitrate, potassium, sodium, calcium and lithium chlorides. The curves for caustic soda were shown to be intermediate between those for sodium and calcium chlorides, and to form one member of a series of progressively changing types. The drooping of the ends of the curves was shown to depend on the occurrence during the preparation of the solutions of a contraction resulting from the formation of hydrates. Such a contraction indicates that water is increased in density by combining with a solute; in order to give definiteness to this conception, the suggestion was made that the density of combined water is similar to that of its denser constituent (dihydrol) in the free state, and that the contraction on dissolution is due mainly to the conversion into hydrate of lighter constituents present in the liquid. As this contraction in the case of lithium chloride solutions increases both above and below $40^{\circ}$, it follows that a lighter form of water is produced, not only by cooling, but also by heating it. The presence of three constituents in the liquid (ice, water and steam, or trihydrol, dihydrol and monohydrol) is indeed absolutely necessary in order to account for the complex changes of volume that have been observed in water and in the solutions prepared from it.

Mr. Sutherland's paper "On the constitution of water" had been circulated before the meeting, and owing to lack of time was taken as read. His suggestion that the hexagonal symmetry of ice crystals may be taken as evidence in favour of the "trihydrol" formula will now receive more serious consideration than would have been the case a few years ago; although his method of deducing the relative sizes of the atoms differs from that made use of by Barlow and Pope, and his method of "packing" is not the "closest" possible, there is no doubt that the general scheme of the arrangement is sound, and that the argument from crystal structure to chemical constitution may now be accepted as both legitimate and useful. Unlike the previous authors, Mr. Sutherland considers that monohydrol does not exist in liquid water, but is present in all salts containing water of crystallisation. He attributes to it a density ( $\mathrm{I} \cdot 3 \mathrm{I}$ in the solid and $\mathrm{I} \cdot 26$ in the liquid state) considerably greater than that of dihydrol (I.13 and 1.09) or of trihydrol (0.92 and 0.88), and in an appendix gives values for a number of its other physical properties.

Prof. Nernst's paper on the specific heat of ice, water and steam was read by Dr. Wilsmore. The survey covered the whole field from $-200^{\circ}$ to the highest temperatures, but attention was directed specially to minima in the specific heat of water vapour under moderate pressures and of liquid water at moderate temperatures; both minima were attributed to the dissociation of complex molecules. The question of specific heats was also dealt with in a note on the specific heat of water of crystallisation by Mr. F. P. Sexton, of Truro, which was read by Dr. J. A. Harker. In the case of copper sulphate the first four nolecules of combined water were found to have a specific heat 0.499 , whilst the fifth molecule gave the value 0.508. Mr. Bousfield pointed out that the value 0.5 also held good for the combined water in solutions of potassium chloride, the heat capacities of which could be calculated correctly by assuming them to be mixtures of free water, hydrate-water, and salt. Dr. Senter pointed out that the values now given agreed well with the view, in support of which much evidence was available, that in compounds such as copper sulphate four molecules of water were definitely associated with the metallic atom, the remainder being perhaps attached to the molecule as a whole.

Early in the evening $\mathrm{Mr}$. H. B. Baker showed a remarkable experiment on the influence of purification in retarding the action of water on sodium amalgam, the underlying idea being that if water could by purification be rendered non-conducting it might also be rendered chemically inactive. Similar experiments on the inactivity of highly purified nitric acid were described by Mr. Veley.

A complimentary dinner, the first in the history of the Faraday Society, was given in honour of its foreign guests, Profs. Walden and Guye, on Wednesday, April 27, under the chairmanship of the president, Mr. James Swinburne, F.R.S. The English guests included Sir William Ramsay, Sir William Tilden, Sir Joseph Larmor, Prof. H. B. Dixon, Prof. Divers, and Dr. Chree. In responding to the toast of the guests of the evening. Prof. Walden referred to the scientific relationship between Russia and Great Britain, remarking, incidentally, that the first Russian chemist was an Englishman, sent by Queen Elizabeth to Russia in the sixteenth century. Prof. Guye dwelt on the debt which chemists all over the world owed to Faraday, and gave an interesting account of Faraday's visit to Geneva when he accompanied Sir Humphry Davy on his tour through Europe.

T. M. L.

\section{RECENT ADDITIONS TO IDEAS REGARDING THE INTERNAL STRUCTURE OF THE} EARTH.

BEYOND the superficial observations made by geologists, not extending more than about one two-hundredth of the radius below the surface, even by indirect means, we are dependent on mathematicians for our ideas regarding the physical state of the earth's interior; these ideas are based on extrapolation from physical constants obtained in the laboratory, and their variety extends to the number of possible permutations and combinations of the three physical states of matter-solid, liquid, and gaseous. Halley's conception of a core and shell rotating at different speeds has been revived by Sir F. J. Evans (1878) and by the distinguished founder of this series of lectures to explain the secular variations of magnetism. The Laplacian hypothesis, based on Clairault's theorem, is now

I Abst act of the Wilde lecture delivered to the Manchester Titerarv and Philosophical Society on March 22, by Sir Thomas H. Holland, K.C.I.E., F.R.S. 
being superseded in many minds by Chamberlin's planetesimal theory, after having inspired petrologists with a vain hope of finding traces of the primeval slaggy crust among the Archæan gneisses. Astronomers prefer a solid globe, but on grounds different from those assumed by Hopkins and at first accepted by Lord Kelvin. Arrhenius concludes in favour of a gaseous core, like that postulated by Ritter, but of larger dimensions than the gaseous core suggested by Dr. Wilde.

Theories regarding the processes of consolidation, the gradient of pressure, and the deep-seated rise in temperature are equally varied. Until this year all agreed in assuming the earth's interior to be hot, but Prof. Schwarz now prefers to think it is cold. So long as radio-active bodies were unknown the apparent reserves of heat-energy offered the world a short life; but its actuarial value has now been increased almost indefinitely by the discovery of radium in embarrassingly large quantities, and Prof. Joly warns us that, instead of peaceful cooling, the present "age " may end in catastrophic heating.

The nearest approach to actual observation regarding the deep-seated parts of the globe is recorded by the seismograph as interpreted by R. D. Oldham, who aptly compares the seismograph with the spectroscope as an instrument for examining inaccessible objects. The first and second phases of long-distance seismographic records, which are due to waves passing through the earth by approximately chordal paths, show a reduction in velocity when there is a sufficient distance between the origin of the shock and the recording instrument for the assumed chordal paths to pass through the inner two-fifths of the earth's core, while the distortional waves are apparently dispersed by refraction when the origin of the earthquake and the recording instrument are separated by about $140^{\circ}$. The records, which are confessedly too few to be regarded as conclusive, suggest that the central core differs in physical characters from the outer three-fifths and the superficial crust. Similarly, the vibrations that pass under the great oceanic depressions indicate elastic conditions differing from those under the continental plateaux, the difference being apparent to a depth of about one-quarter the earth's radius. This last conclusion might be correlated with the variation in the chemical composition in the sub-oceanic crust caused by selective denudation of the kind indicated by Sir John Murray in 1899 , and by Chamberlin's theory regarding the origin of the oceanic depressions.

The recent discussions and new data obtained by geodesists and geologists to check Dutton's theory of isostasy have revived interest in the deep-seated parts of the superficial crust. The remarkable work recently done in India by Burrard and Lenox-Conyngham, when correlated with the results of the Geological Survey, are especially important in showing the truth and the limitations of isostasy. Burrard's results indicate that the Himalayan heights are partly compensated by deficiencies of subterranean gravity, and that greater loads are maintained by the rigidity of the geologically stable crust of the peninsula than in the folded parts of the extrapeninsular region. The deficiency of gravity under the outer and sub-Himalaya is, however, equally pronounced in the plains near the southern foot of the range; but at a distance of about 150 miles from the foot of the mountains there is a subterranean band of high gravity parallel to the alluvium-filled Gangetic valley, as well as to the four Himalayan zones-the foot-hills, composed of Tertiary strata; the outer Himalaya, of much older, unfossiliferous sediments; the crystalline range of snow-covered peaks; and the Tibetan highlands of fossiliferous, marine strata.

Soon after Dutton published his theory of isostasy, $R . S$. Woodward pointed out that, if the highlands continued to rise in consequence of the reduction in their load by erosion, and the depressions continued to sink under the growing weight of accumulating sediment, the process should continue indefinitely, and mountain ranges would thus never be worn down, while new folds in undisturbed areas would never arise; but the geological history of India shows why and how this process may result in "isostatic suicide." For ages before the end of the Mesozoic era the rivers of Gondwanaland, which stretched away as a great continent to the south and west, poured NO. 2 I I 4, VOL. 83 ] their loads of silt into the Eurasian ocean, of which the southern shore-line approached the line now occupied by the Himalayan snow-covered peaks. With the loading down of the northern littoral of Gondwanaland, the northern part of the continent became stretched, and normal faults were developed with a general east to west trend.

Some of the faults of this kind occurring in the Central Provinces were shown by J. G. Medlicott, so long ago as 1860 , to be pre-Gondwana (that is, pre-Carboniferous) in age, others were formed before the Upper Gondwana (Lower Mesozoic) strata were formed, while the latest affected the younger Gondwana beds, and became channels for the Upper Cretaceous basalts. The general trend of the Cretaceous dykes in this part of India, and the prevalence of normal faults further east at about the same latitude, shown in various geological maps published by later members of the Geological Survey, indicate the nature and direction of the tension produced by the unloading of Gondwanaland and the simultaneous depression of the adjoining ocean bed. The process reached its climax towards the end of Cretaceous times, when the basaltic magma below welled out and flooded more than 200,000 square miles to a depth of nearly a mile.

Presumably the tension marked by faults in Central India existed also in areas further north, where the records are now buried under the Gangetic alluvium, and the band of high gravity detected by Burrard's plumb-line and pendulum is probably due to concealed batholiths of basic and ultra-basic magma, which were injected into the region of tension after the manner described by Prof. R. A. Daly. ${ }^{1}$ Then followed the production of a geosyncline parallel to the northern shore-line of the old Gondwana continent and parallel to the subsequent folds of the Himalayan range, which are now being thrust over towards the region of deficient gravity between the visible mountain range and the concealed band of basic batholiths.

The data in this area are in substantial agreement with Daly's idea of a persistent sub-crustal gabbroid magma, which, though possibly only in a state of potential fusion under regions of normal pressure-gradient, may become fluid in localities of protracted erosion and gradual rise of the northern shore-line of the old Gondwana continent and agree, in general, with those analysed by Hayford and others in America in showing that isostasy can be detected only when the visible masses over wide areas are concerned; further data of this kind will permit of the determination of the minimum loads that can be maintained by the crust in old stable land surfaces as compared with the apparently smaller loads maintained in recently folded regions. If the sequence of events in India has been correctly traced, it should be possible to indicate areas on the earth which are in danger of basaltic floodings and of later folding movements. In South America, for instance, the northflowing tributaries of the Amazon and the Araguaya are possibly developing conditions on the old land surface of Brazı similar to those that on Gondwanaland preceded the outburst of the Deccan Trap in Cretaceous times.

\section{THE HULA, OR FOLK-DRAMA OF HAWAII.}

THE Hula, or national folk-drama of Hawaii, has already been casually described by the Rev. W. Ellis in his "Polynesian Researches," and has been noticed in the "Travels" of Captain Cook; but it was left to Dr. N. B. Emerson to undertake a detailed investigation of the unwritten literature of the island, and to make a collection of the songs sung in these performances. The results of this study have been published in Bulletin No. 38 of the American Bureau of Ethnology. We may congratulate this institution on having now, for the first time, under the authority of a special Act of Congress, extended its operations beyond the bounds of the American continent.

The Hula is a special form of folk-drama, dealing in a series of impassioned lyrics with many phases of the national mythology and traditions. The poetry is of a highly romantic and sensuous type, including themes connected with human love and life, the processes of nature, 1 "Abyssal Injection as a Causal Condition and as an Effect of Mountain-
building," by R. A. Daly (Amcr. Journ. Sci., xxi'., r9o6, pp. 207-1.3). 